\title{
A PROTEÇÃO DE MARCAS SETORIAIS DO MUNDO DA MODA DESTINADAS À INSERÇÃO NO MERCADO INTERNACIONAL
}

DOI: http://dx.doi.org/10.18616/pidi17

Patrícia Maria da Silva Barbosa - INPI/UFRJ

E-mail:pmdsbl@gmail.com Leopoldo Nascimento Coutinho - INPI/UFF E-mail: leopoldo.coutinho@gmail.com Pablo Ferreira Regalado - INPI/ISEG 


\section{INTRODUÇÃO}

Uma parcela da iniciativa privada, em geral, necessita de apoio inicial para se desenvolver e crescer diante dos obstáculos que surgem de tempos em tempos na economia mundial. Os governos, por sua vez, criam estruturas próprias a fim de atender a essa demanda de determinados segmentos mercadológicos, como é o caso da indústria da moda, que, no Brasil, vem se destacando em busca de novos mercados para além das fronteiras do país.

Em nosso país, a principal entidade governamental voltada para o estímulo da internacionalização da indústria nacional é a Agência Brasileira de Promoção às Exportações - ApexBrasil, a qual estimula setores estratégicos para o desenvolvimento da competitividade das empresas brasileiras e do próprio país por meio de diversas ações denominadas Projetos Setoriais, as quais são o enfoque do presente capítulo.

Um dos objetivos deste estudo é verificar se outros países economicamente significantes para o macrossetor selecionado - indústria da moda - possuem políticas de estímulo no formato da agência brasileira, isto é, por segmento mercadológico. Para tanto, as experiências dos Estados Unidos e da Itália serão discutidas, além das do Brasil. O primeiro país, em razão da sua representatividade no cenário comercial internacional. O segundo, devido à sua grande reputação nesse ramo e à alta qualidade associada aos produtos em si originados.

Objetiva-se, também, identificar a proteção por meio de ativos de propriedade industrial, nomeadamente as marcas setoriais desses países e se desempenham um papel estratégico no posicionamento das empresas no segmento em estudo ou não.

Para atingir tais objetivos, este capítulo encontra-se estruturado da seguinte forma: inicia-se com a contextualização da indústria da moda, seguida da apresentação do modo de internacionalização desse segmento adotado pelo Brasil. Em seguida, identificam-se as linhas de atuação norte-americanas e italianas, buscando conhecer as ações de estímulo ao comércio, bem como a existência ou não de programas específicos para o segmento. No último tópico, são analisadas as estratégias de proteção marcária, com enfoque setorial, encontradas. Encerra-se o estudo com as considerações finais sobre o tema. 


\section{COMÉRCIO EXTERIOR E O MUNDO DA MODA - ALGUNS ASPECTOS}

Ultrapassar fronteiras e conquistar domínios já foram sinônimos de estabelecimento de colônias político-geográficas mundo afora. Hoje em dia, não mais. No século XXI, a chamada globalização está vinculada ao estabelecimento do acesso a um mercado específico, abrindo espaço para que as empresas nacionais tenham a possibilidade de se transformarem em ultranacionais, gerando, produzindo e vendendo em cadeias logísticas que abrangem distintos países.

A indústria têxtil (e de vestuário) ocupa um papel histórico nesse cenário, pois se constitui em uma das atividades tradicionais na passagem da manufatura para a grande indústria (LUPATINI, 2004, p. 31). É um dos setores mais difundidos espacialmente, em termos mundiais, e uma notável fonte de geração de emprego e renda para vários países, concentrando $15,7 \%$ da produção manufatureira mundial, $8.3 \%$ do valor dos produtos manufaturados comercializados no mundo e mais de $14 \%$ do emprego mundial, de acordo com dados do American Textile Manufacturers Institute - ATMI (LUPATINI, 2004, p. 34). ${ }^{19}$

Na presente seção, será destacado o comportamento dos países escoIhidos para o estudo - Brasil, Estados Unidos e Itália -, com vistas a identificar o modo pelo qual estimulam a exportação setorial. A partir desse exercício, pretende-se avaliar os diferentes cenários nacionais, de modo a comparar os casos e discutir a existência de proteção marcária específica por segmento.

\section{BRASIL}

Conforme exposto, a principal entidade governamental voltada para o estímulo da internacionalização da indústria nacional é a ApexBrasil. Trata-se de uma agência executiva que realiza ações diversificadas de promoção comercial e que visa intensificar as exportações e valorizar os produtos e serviços brasileiros no exterior.

\footnotetext{
${ }^{19}$ Para mais informações sobre globalização e comércio exterior, verificar: CHESNAIS, François. A globalização e o curso do capitalismo de fim-de-século. Tradução de Catherine Marie Mathieu. Economia e Sociedade, Campinas, n. 5, p. 1-30, dez. 1995, e CASTELLS, Manuel. A Sociedade em Rede. Vol. 1. Tradução de Roneide Venanciocom Majer, com a colaboração de Klauss Brandini Gerhardt. 8. ed. São Paulo: Paz e Terra, 2005.
} 
A fim de atingir esse objetivo, a agência é responsável por coordenar os esforços de atração de investimentos estrangeiros diretos para o Brasil. Foca em setores estratégicos para o desenvolvimento da competitividade das empresas brasileiras e do país, investindo em diversas ações, tais como visitas de compradores estrangeiros e formadores de opinião para conhecer a estrutura produtiva brasileira, por exemplo. Outra linha de ação é composta por missões prospectivas e comerciais, rodadas de negócios e apoio à participação de empresas brasileiras em grandes feiras internacionais.

Nesse contexto, a instituição com ativos da ordem de 200 milhões de reais (APEXBRASIL, 2016) ${ }^{20}$ definiu campos de atuação em parceria com as entidades empresariais, criando os chamados Projetos Setoriais, os quais visam criar soluções de promoção comercial apropriadas a cada setor produtivo, assim como adequadas à maturidade exportadora de cada empresa interessada em se inserir no mercado externo, considerando seu porte e localização.

Atualmente, os setores contemplados com ações específicas por Projetos Setoriais próprios são os segmentos de alimentos e bebidas; agronegócios; casa e construção; economia criativa; máquinas e equipamentos; tecnologia; saúde; e moda (APEXBRASIL, 2016). ${ }^{21} \mathrm{O}$ interesse do presente estudo recai sobre o último: o Projeto Setorial voltado para o mundo da moda, segmento esse considerado o segundo maior gerador de emprego na indústria de transformação no Brasil, com aproximadamente 33 mil empresas registradas formalmente, segundo dados da Associação Brasileira da Indústria Têxtil e de Confecção - ABIT ( $A B I T$, s.d.). Ainda segundo a ABIT, essa indústria desenvolve-se há quase 200 anos no País, sendo o Brasil a última cadeia têxtil completa do ocidente, pois é o único país a possuir desde a produção de fibras (por meio de plantações de algodão) até os desfiles de moda, perpassando por fiações, tecelagens, beneficiadoras, confecções e forte varejo (ABIT, s.d.). Além disso, o Brasil é referência mundial em design de moda praia, jeanswear e homewear, tendo crescido também os segmentos de fitness e lingerie (ABIT, s.d.) $)^{22}$. Tais dados incentivaram o interesse em analisar a presença de possíveis marcas com cunho setorial que, por ventura, existam no setor.

\footnotetext{
${ }^{20}$ Demonstrativo Financeiro de 31 de março de 2016. Disponível em: <http://www.apexbrasil.com.br/ uploads/marc\%CC\%A7o-2016.pdf>. Acesso em: 12 ago. 2016.

${ }^{21}$ Disponível em: <http://www.apexbrasil.com.br/participe-dos-nossos-projetos-com-as-entidades-setoriais>. Acesso em: 12 ago. 2016.

${ }^{22}$ Disponível em: <http://www.abit.org.br/cont/perfil-do-setor>. Acesso em: 12 ago. 2016.
} 
Considerando a complexidade do segmento, o Projeto Setorial Moda da APEX é dividido em oito subprojetos, os quais observam as características particulares de setores específicos. São eles: artefatos de couro; calçados e acessórios; têxtil e confecções; couros; componentes para calçados; design e moda; gemas e joias; e, por último, o subprojeto denominado Multissetorial (APEXBRASIL, 2016).

Visando facilitar a comparação com a experiência das demais agências de promoção à exportação em outros países, optou-se por uma redução de escopo. Desse modo, o presente capítulo terá como enfoque apenas os três primeiros subprojetos, isto é, os subprojetos destinados aos artefatos de couro, aos calçados e acessórios e ao têxtil e confecções (Quadro 1).

Quadro 1 - Subprojetos Setoriais promovidos pela ApexBrasil na indústria da moda

\begin{tabular}{|c|c|c|c|c|}
\hline Subprojetos Setoriais & Parceiros gestores & $\begin{array}{c}\text { Atividades } \\
\text { implantadas }\end{array}$ & $\begin{array}{c}\text { Mercados- } \\
\text { Alvo }\end{array}$ & Resultados \\
\hline $\begin{array}{l}\text { Artefatos de Couro } \\
\text { Brasil By Bags } \\
\text { (http://www.brasilbybags.com) } \\
\text { Ano de lançamento: } 2014\end{array}$ & $\begin{array}{l}\text { ABIACAV - } \\
\text { Associação Brasileira } \\
\text { das Indústrias de } \\
\text { Artefatos de Couro } \\
\text { e Artigos de Viagem }\end{array}$ & 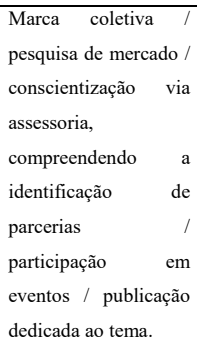 & $\begin{array}{l}\text { Estados Unidos, } \\
\text { Colômbia, } \\
\text { Chile, Costa } \\
\text { Rica, Peru, } \\
\text { França, Rússia } \\
\text { (+14 destinos). }\end{array}$ & $\begin{array}{l}85,3 \% \text { do total exportado pelo } \\
\text { setor no primeiro semestre de } \\
2015 \text {; montante exportado: US\$ } \\
460 \text { mil dólares (mais da metade } \\
\text { de } 2015^{1} \text { ). Em } 2015,18 \text { ações, } 37 \\
\text { empresas, US\$ (FOB) } 539 \text { mil em } \\
\text { exportações (até outubro). } \\
\text { Participação do projeto nas vendas } \\
\text { externas representou } 16 \% \text { do total, } \\
\text { quatro vezes mais do que em } 2014 .\end{array}$ \\
\hline $\begin{array}{l}\frac{\text { Calçados e Acessórios }}{\text { Brazilian Footwear }} \\
\text { (www.brazilianfootwear.com.br) } \\
\text { Ano de lançamento: } 2000\end{array}$ & $\begin{array}{l}\text { ABICALÇADOS - } \\
\text { Associação Brasileira } \\
\text { das Indústrias de } \\
\text { Calçados }\end{array}$ & $\begin{array}{l}\text { Marca coletiva / } \\
\text { desenvolvimento de } \\
\text { imagem e viabilização } \\
\text { de parcerias } \\
\text { participação em } \\
\text { eventos / campanhas } \\
\text { publicitárias } \\
\text { editoriais de moda. }{ }^{2}\end{array}$ & $\begin{array}{l}\text { Estados Unidos, } \\
\text { México, } \\
\text { Colômbia, } \\
\text { China, Emirados } \\
\text { Árabes Unidos, } \\
\text { Alemanha e } \\
\text { Rússia. }\end{array}$ & $\begin{array}{l}\text { Incremento de mais de } 50 \% \text { no } \\
\text { número de destinos comercias } \\
\text { para o produto brasileiro ( } 150 \text { no } \\
\text { total ao final de 2013). }\end{array}$ \\
\hline
\end{tabular}




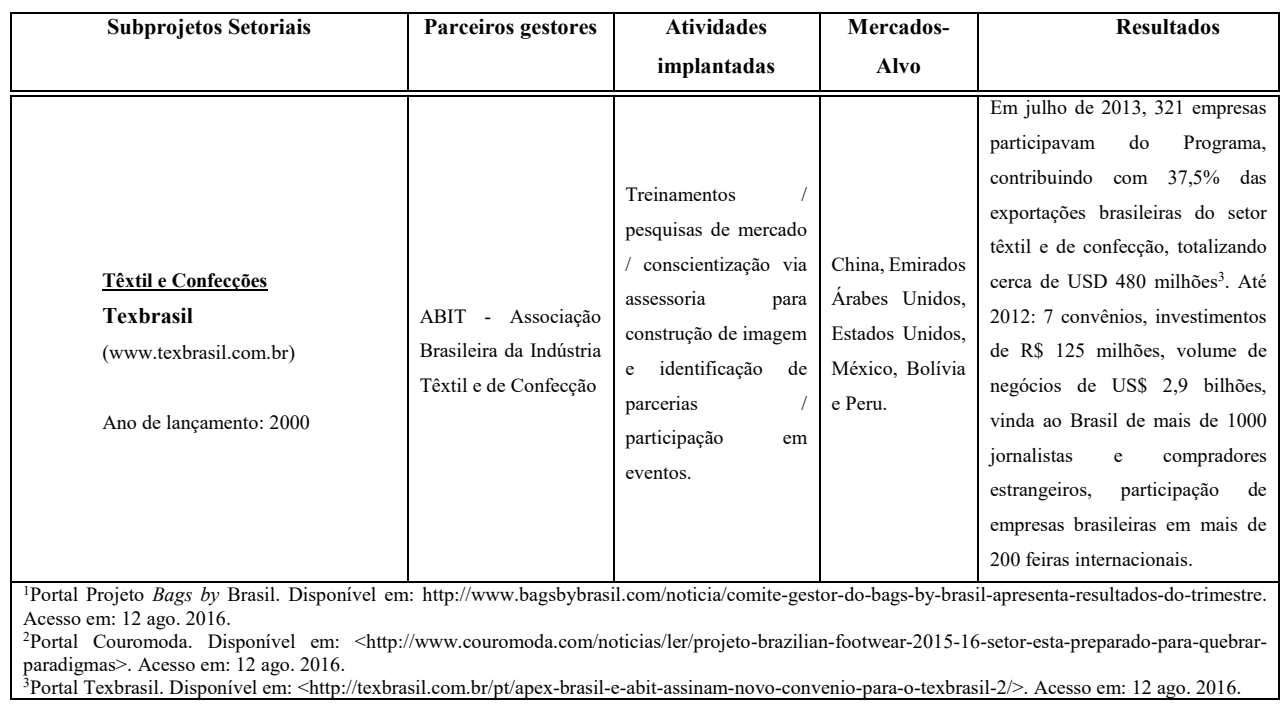

Fonte: Elaborado pelos autores.

Conforme se depreende do Quadro 1, cada subprojeto é gerido por uma entidade coletiva ligada ao segmento que, ao longo do tempo, desenvolve características próprias de gestão para obtenção de resultados diversos em prol das empresas envolvidas. No entanto, comparações de resultados não são fáceis de serem feitas devido ao perfil diferenciado dos participantes.

Implica na avaliação dos resultados apresentados no Quadro 1 observar que o primeiro projeto é mais recente, iniciado há apenas dois anos, isto é, em 2014, enquanto os demais iniciaram em 2000. Também influencia diretamente nessa comparação que a publicidade dos resultados obtidos é feita de forma divergente pelas entidades. No entanto, foi possível identificar que, em comum, todos os projetos analisados apresentaram como resultados incremento em exportações e em número de países atingidos ao longo do desenvolvimento do projeto.

A avaliação do desempenho dos Projetos Setoriais é apontada pelo Relatório Anual de Auditoria de Contas prestadas pela ApexBrasil na Controladoria Geral da União - CGU, porém o único relatório ao qual o presente estudo teve acesso foi o referente ao exercício de $2012 .{ }^{23}$ Nele, no que tange ao Brazilian

${ }^{23}$ BRASIL. Controladoria Geral da União. Secretaria Federal de Controle Interno. Relatório de Auditoria Anual de Contas - ApexBrasil 2012. Relatório no 201308611. Brasília, DF, 26 de fevereiro de 2013. Disponível em: <http://www.cgu.gov.br/relatorios-antigos/RA201308611>. Acesso em: 12 ago. 2016. 
Footwear, graças às ações de promoção comercial, imagem e competitividade, as empresas participantes tiveram um desempenho melhor que o resultado das exportações totais do País. O TexBrasil, por sua vez, não conseguiu alcançar os resultados esperados no período 2010/2011 por causa da entrada da China na Organização Mundial do Comércio - OMC e da diminuição dos limites expostos para vender têxteis e confecção no mercado externo.

Considerando que o Relatório localizado é de 2012, data anterior ao projeto Brasil By Bags, que iniciou em 2014, o resultado é que ele não disponibiliza dados, infelizmente.

Será que essa mesma estratégia, por setores, é seguida em outros países? Será que eles têm a mesma construção dos casos aqui identificados? Essas questões serão discutidas nas próximas seções.

\section{ESTADOS UNIDOS}

A China desbancará os Estados Unidos como maior mercado de vestuário e calçados do mundo, em 2017, afirma relatório publicado pelo Banco Mundial. ${ }^{24}$ Mas enquanto isso não acontece, parece interessante verificar o modo como o governo norte-americano se posiciona para impulsionar suas empresas rumo ao mercado externo.

A International Traders Associates (ITA) ${ }^{25}$ é o organismo responsável por apoiar as empresas norte-americanas na sua caminhada pelo mercado internacional. Com esse fim, criou-se uma plataforma específica para a temática exportação ${ }^{26}$ em que podem ser encontrados diversos serviços, segmentados por indústrias, inclusive aquela que engloba os três campos abordados no presente estudo - calçados, artefatos de couro e têxtil e confecções ${ }^{27}$. Tais serviços seriam:

\footnotetext{
${ }^{24}$ SINDIVESTUÁRIO. China ultrapassa Estados Unidos como maior mercado de vestuário e calçados. Publicado em 2014. Disponível em: <http://sindivestuario.org.br/2014/06/china-ultrapassa-estados-unidos-como-maior-mercado-de-vestuario-e-calcados/>. Acesso em: 12 ago. 2016.

${ }^{25}$ Para mais detalhes sobre a ITA, ver: <http://www.italtrade.com/about/about_us.htm>. Acesso em: 22 set. 2016.

${ }^{26}$ EXPORT.GOV. Sem data. Disponível em: <www.export.gov>. Acesso em: 22 set. 2016.

${ }^{27}$ Nos EUA, chamam de Textiles, Apparels and Sporting Goods tecidos, vestuário e bens esportivos (tradução livre). Para mais detalhes sobre esse setor específico e seus programas, ver: <http://www. export.gov/industry/apparel/index.asp>. Acesso em: 22 set. 2016.
} 
- Acompanhamento de eventos temáticos pelo mundo;

- Base de dados, facilitando a localização de produtores locais pelos importadores internacionais;

- Guias para orientação sobre a entrada em mercados externos;

- Divulgação de temas de interesse do exportador, com um buscador eletrônico específico para a matéria identificada;

- Vídeos sobre mercados de grande potencial;

- Pesquisas de mercado e relatórios especialmente produzidos pelos adidos comerciais norte-americanos espalhados pelo mundo.

As linhas de trabalho supracitadas aparentemente abrangem todo o tipo de indústria do mercado interno; portanto, não há distinção específica pelo governo norte-americano para a indústria da moda. Os Estados Unidos são um grande mercado consumidor, não apenas pelo tamanho de sua população como também pelo seu poder aquisitivo, sendo capazes de manter a posição de maiores importadores mundiais, mesmo durante o período de crise nos anos de 2008 e $2009^{28}$. Os autores supõem ser esse cenário influenciador da política encontrada, com abordagem genérica em termos de táticas de ataque aos mercados externos.

\section{ITÁLIA}

A Italian Trade Promotion Agency (ITA) ou Agência Italiana de Promoção ao Comércio Exterior - ICE é uma organização governamental voltada à internacionalização das empresas daquele país mediterrâneo. Segue as diretrizes estabelecidas pelo Ministério do Desenvolvimento Econômico, provendo todo tipo de informação, apoio e consultoria, tanto para as empresas italianas que buscam o mercado externo quanto para as empresas estrangeiras que têm interesse em investir no mercado italiano.

${ }^{28}$ BRASIL. Portal do Brasil. Brasil promove produtos de moda e design no mercado norte-americano. Publicado em 17 de abril de 2012. Disponível em: <http://www.brasil.gov.br/governo/2012/04/brasil-promove-produtos-de-moda-e-design-no-mercado-norte-americano>. Acesso em: 22 set. 2016. 
Seus principais objetivos são (ITA, s.d.): ${ }^{29}$

- Identificar parceiros comerciais;

- Promover encontros bilaterais de comércio com a participação de empresas italianas;

- Promover a visita de delegações de comércio estrangeiras à Itália;

- Participar (ou incentivar a participação) de eventos internacionais de comércio (feiras, exibições, etc.);

- Desenvolver fóruns e seminários com especialistas italianos.

Para atingir tais objetivos, a ITA utiliza diferentes ferramentas, no entanto, mais uma vez, a abordagem adotada é distinta da brasileira, não possuindo projetos setoriais com participação governamental direta na sua gestão.

Do mesmo modo que a experiência norte-americana antes discutida, existe uma predisposição do governo italiano para fornecer o máximo de informações possíveis para suas empresas sobre os potenciais mercados externos consumidores dos produtos made in Italy. Assim é dada ao empresário a possibilidade de decidir a melhor estratégia para conduzir a inserção de sua empresa no mercado global, não havendo uma participação ativa do governo nesse processo decisório.

Interessante observar que, no caso específico dos produtos vinculados à indústria da moda, que são o foco deste capítulo, a política acima sinalizada se demonstra mais forte ainda, quase que delegando à iniciativa privada as principais políticas de expansão ${ }^{30}$.

Os autores supõem que essa postura talvez esteja relacionada à própria estrutura interna e à reconhecida qualidade do produto italiano. Nem mesmo no Portal da ICE ${ }^{31}$, que promove os produtos feitos na Itália, o setor em estudo é elencado.

\footnotetext{
${ }^{29}$ ITALIAN TRADE AGENCY - ITA. Sem dada. Disponível em: <http://www.italtrade.com/about/about_ us.htm>. Acesso em: 22 set. 2016.

${ }^{30} \mathrm{Um}$ exemplo de projeto da iniciativa privada nesse sentido está disponível no site http://www.italianmoda.it/, o qual propicia o acesso direto a alguns produtores daquele país. Outro exemplo, de caráter mais genérico, encontra-se disponível em http://www.made-in-italy.com.

${ }^{31}$ Disponível em: <http://www.italtrade.com/countries/links/industries.htm>. Acesso em: 22 set. 2016.
} 
O interessado que atua no mundo da moda deve acessar outras fontes de informação na busca de assessoria em comércio internacional, conforme demonstrado, a seguir, na Figura 1:

Figura 1 - Dados sobre a indústria da moda italiana e os mercados externos

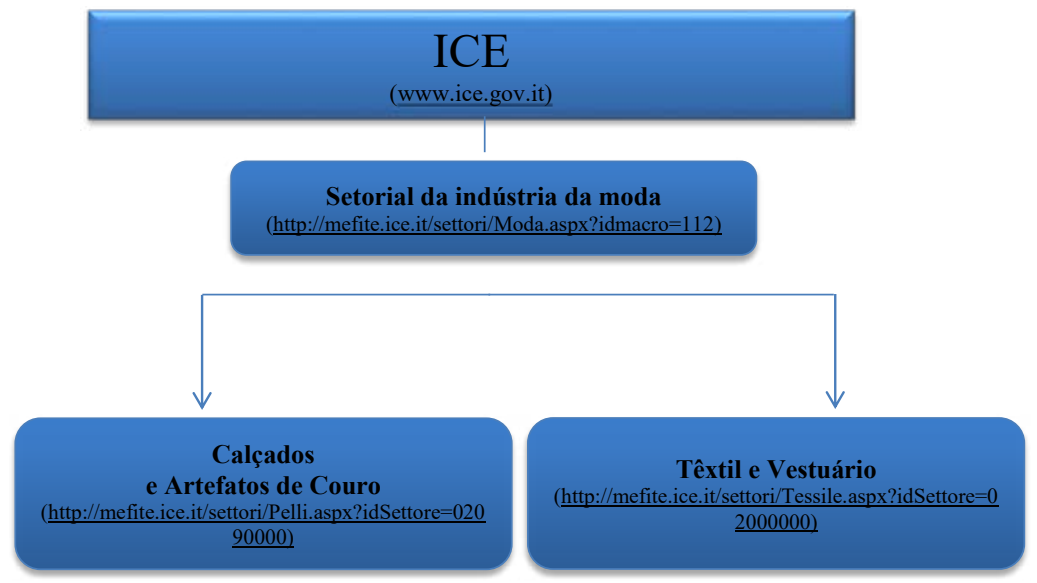

Fonte: Elaborada pelos autores.

Por intermédio desses canais, é possível saber que a Itália é a terceira maior exportadora de tecidos e vestuário do mundo. Encontra-se atrás apenas da China e da Alemanha, gerando um superávit comercial, que somente é superado pelo setor de metalomecânica. Os principais mercados atingidos pelos produtos italianos são o europeu, o russo, o norte-americano e o japonês, com especial atenção para o aumento recente de importância do volume voltado para o mercado asiático como um todo (PORTAL ICE, s.d.).

Já no mercado calçadista, a Itália é a 10a colocada em termos de volume exportado, correspondendo a $1,7 \%$ do total. Os principais mercados consumidores são Japão, EUA e Rússia, com um incremento relevante dos demais países do Leste Europeu. O mercado para o couro italiano segue a mesma lógica, sendo beneficiado pelo incremento da renda de mercados emergentes como China, Leste Europeu, Emirados Árabes Unidos, Arábia Saudita, Cazaquistão e Ucrânia (PORTAL ICE, s.d.).

O apoio se dá, principalmente, via suporte à participação em feiras internacionais, identificação de oportunidades de parceiras comerciais, acompanhado do acesso a dados estatísticos e relatórios sobre mercados específi- 
$\cos ^{32}$. Nesse último aspecto, é interessante observar a atuação do Ministério de Assuntos Externos e Cooperação Internacional ${ }^{33}$, que reconhece a importância de estabelecer parcerias e de inserir o produto italiano no mercado global.

Nas próximas seções, o enfoque será a cultura de proteção da propriedade industrial, nomeadamente via marcas, sobretudo de natureza coletiva, por parte de quem atua na indústria da moda, tanto no Brasil quanto nos Estados Unidos e na Itália. Alguns conceitos e dados serão utilizados a fim de demonstrar o emprego (ou não) da proteção no Instituto Nacional da Propriedade Industrial - INPI brasileiro.

\section{A PROTEÇÃO DOS NOMES DOS SUBPROJETOS SETORIAIS BRASILEIROS COMO MARCA}

Já foi dito que, no Brasil, o Projeto Setorial Moda se divide em diversos subprojetos, dos quais o presente estudo aborda artefatos de couro, calçados e acessórios, bem como têxtil e confecções. Isso porque são atividades que visam fortalecer e destacar a origem brasileira, ou seja, promover a "marca Brasil" mundo afora. Segundo Iversen e Hem (2008), três são as formas de um país ter a imagem associada a uma marca:

1- Uso de marcas individuais para diferentes produtos, sem menção explícita do país de origem;

2- Uso de marcas e submarcas, com a combinação do nome da marca com o país de origem;

3- Uso do conjunto da marca com o local de origem.

No primeiro caso, a nacionalidade se estabelece na mente dos consumidores ao longo do tempo, sem haver divulgação conjunta, sendo essa a estratégia na segunda forma apresentada. A terceira, por sua vez, é onde o país pode desenvolver um nome compartilhado para todos os seus produtos e serviços, dentro de uma categoria ou setor, sendo assim chamada de "marca setorial".

\footnotetext{
${ }^{32}$ No Portal da ICE, faz-se necessário um cadastro para ter acesso a tais dados.

${ }^{33} \mathrm{http}: / /$ www.infomercatiesteri.it/ é o portal que destaca tais informações por setores, prescindindo de um cadastro, a princípio, por parte do interessado. Acesso em: 22 set. 2016.
} 
No entanto, evocar o nome do país de origem nem sempre pode ser considerado um benefício. Lourenção e Giraldi (2015) citam como exemplo a "marca Brasil" do Instituto Brasileiro de Turismo - EMBRATUR, a qual pode ser útil para identificar setores interessados em transmitir a imagem de um país alegre, receptivo e multicultural. Porém ela pode não ser a desejada por setores ligados a inovações tecnológicas, sendo necessário que construam uma marca específica. Essa é uma estratégia viável para setores competitivos internacionalmente, empenhados em destacar outros atributos de qualidade e diferenciação (CAPELLARO, 2013; REGALADO et al., 2015).

Uma das ações da ApexBrasil é justamente estimular que Projetos e Subprojetos Setoriais criem marcas próprias para se identificarem. Inclusive, em 2009, foi publicado o Termo de Referência para Desenvolvimento de Marcas Setoriais (APEXBRASIL, 2009).

O Termo solicita a identificação dos atributos e diferenciais dos produtos do setor em relação aos concorrentes; a criação da identidade visual e da linguagem integrada para toda a comunicação a ela relacionada; a definição do posicionamento desejado da marca, chamado Positioning Statement; assim como ações estratégicas para ativação da marca, a fim de alcançar esse posicionamento, entre outros. O Termo destaca, ainda, a importância de haver direitos de propriedade intelectual sobre o produto resultante e, por fim, o registro da marca (LOURENÇÃO; GIRALDI, 2015).

Para os autores deste estudo, existe uma natureza de marca que se enquadra perfeitamente aos objetivos dos Projetos e Subprojetos Setoriais da ApexBrasil e que está prevista na Lei $n^{\circ}$ 9.279/96 - Lei da Propriedade Industrial ou LPI (BRASIL, 1996). Trata-se da Marca Coletiva, definida no art. 123, inciso III, da LPI como "[...] aquela usada para identificar produtos ou serviços provindos de membros de uma determinada entidade" (BRASIL, 1996, n.p.). Portanto, é uma marca destinada ao uso por diversos atores, sendo coletiva por essa razão e não sob o prisma da titularidade (REGALADO et al., 2015).

Marca dessa natureza só deve ser requerida por pessoa jurídica representativa de coletividade, que poderá exercer atividade distinta da de seus membros (BRASIL, 1996, parágrafo 20 do art. 128). Logo, a entidade titular não precisa ser produtora ou prestadora do serviço a ser protegido. É importante, todavia, ter bom senso, de modo que a atividade da entidade titular deve guardar certa relação com o produto ou o serviço que a marca visa assinalar, sendo vedado o registro por pessoas físicas. 
Característica singular da Marca Coletiva é a necessidade de conter o chamado Regulamento de Utilização, que deve ser apresentado no ato do depósito do pedido ou em até 60 dias. Tal documento é de apresentação obrigatória e nele estão presentes as condições e proibições de uso da marca, conforme o art. 147 da LPI.

Regalado et al. (2015) expõem os itens que não podem faltar no Regulamento de Utilização, atendendo ao disposto no art. 3ㅇ da Instrução Normativa INPI/PR nº 19/2013 (BRASIL, 2013, n.p.), a saber:

a) descrição da pessoa jurídica requerente, indicando sua qualificação, objeto social, endereço e pessoas físicas ou jurídicas autorizadas a representá-la;

b) condições para eventual desistência do pedido de registro ou renúncia, parcial ou total, do registro da marca; requisitos necessários para a afiliação à entidade coletiva e para que as pessoas, físicas ou jurídicas, associadas ou ligadas à pessoa jurídica requerente, estejam autorizadas a utilizar a marca em exame;

c) condições de utilização da marca, incluindo a forma de apresentação e demais aspectos referentes ao produto ou serviço a ser assinalado;

d) eventuais sanções aplicáveis no caso de uso inapropriado da marca".

Tal documento pode elencar as características que o consumidor obterá ao adquirir tal produto, assim como pode fornecer informações que concedam segurança, já que tais itens serão produzidos obrigatoriamente com tais características.

Em um mercado onde temas como qualidade, segurança, rastreabilidade e determinação de origem tornam-se cada vez mais importantes, tais marcas informam atributos que os consumidores não podem perceber pelos seus cinco sentidos.

Segundo Barbosa e Regalado (2013, p. 5):

A valorização do produto através da informação contida nestes sinais baseia-se na relação de confiança entre produtor-consumidor, o que confere ao detentor da marca uma vantagem competitiva. Esta vantagem, no caso da marca coletiva, é ainda incrementada ao considerarmos que os custos e os riscos da implementação de uma marca própria no mercado são divididos pela coletividade. 
Portanto, não restam dúvidas de que o Regulamento de Utilização pode servir de instrumento de gestão dos membros da entidade em nome de quem está a Marca Coletiva. Atender aos itens acima certamente influenciará de modo positivo as características desejadas e a qualidade dos produtos/serviços (BARBOSA; REGALADO, 2013).

O problema é que muitos ainda desconhecem as marcas dessa natureza e, talvez, por isso, ainda haja grande quantidade de erros por parte dos requerentes. O INPI recebe os pedidos de registro de Marcas Coletivas e arquiva, definitivamente, aqueles que não possuem Regulamento de Utilização. Muitas vezes, os requerentes nem são entidades representativas de coletividade. Nesses casos, cometem equívoco no preenchimento da natureza da marca no formulário. Isso porque as marcas podem ser classificadas quanto à natureza em marcas de produto, de serviço, coletiva ou de certificação ${ }^{34}$.

Mas será que os Projetos e Subprojetos Setoriais vêm utilizando corretamente essa ferramenta de proteção? Para responder à pergunta, mostra-se, a seguir, o panorama de como a proteção das marcas que identificam os Subprojetos em estudo está acontecendo no INPI ${ }^{35}$. O Quadro 2 ilustra as seguintes situações:

Quadro 2 - Os pedidos e registros de marcas dos Subprojetos Setoriais no INPI

\begin{tabular}{|c|c|c|c|}
\hline Subprojeto Setorial & Marca & Natureza & Status \\
\hline $\begin{array}{l}\text { Artefatos de Couro } \\
\text { Brasil By Bags } \\
\text { Titular: ABIACAV }\end{array}$ & $\begin{array}{l}\text { Brasih } \\
\text { bags }\end{array}$ & $\begin{array}{l}2 \text { Coletivas } \\
\\
\end{array}$ & $\begin{array}{l}\text { Arquivamento do } \\
\text { pedido por não } \\
\text { cumprimento de } \\
\text { exigência }\end{array}$ \\
\hline $\begin{array}{l}\text { Calçados e Acessórios } \\
\text { Brazilian Footwear } \\
\text { Titular: ABICALÇADOS }\end{array}$ & Brazilian Footwear & 3 Coletivas & Marcas registradas \\
\hline $\begin{array}{l}\text { Têxtil e Confecções } \\
\text { Texbrasil } \\
\text { Titular: ABIT }\end{array}$ & & $\begin{array}{l}4 \text { de Produto e } \\
2 \text { de Serviço } \\
\text { X }\end{array}$ & Marcas registradas \\
\hline
\end{tabular}

Fonte: Base de Dados de Marcas. INPI (s.d).

\footnotetext{
${ }^{34}$ Para mais informações sobre a natureza das marcas e sobre os formulários de depósito no INPI, consultar <http://www.inpi.gov.br/menu-servicos/marcas>. Acesso em: 22 set. 2016.

${ }^{35}$ É oportuno ressaltar que não basta registrar a marca no INPI. Para realmente cumprir sua função, ela deve chegar ao mercado e ter as suas características particulares difundidas entre os consumidores.
} 
Em uma análise dos três Subprojetos Setoriais, é possível constatar que a Associação Brasileira das Indústrias de Artefatos de Couro e Artigos de Viagem - ABIACAV não demonstrou interesse por suas Marcas Coletivas diante do arquivamento definitivo dos pedidos. As razões podem ser diversas. Uma delas é a mudança de estratégia, optando por uma nova identidade visual. No entanto, até o momento, não existem novos pedidos depositados no INPI.

Por outro lado, a Associação Brasileira das Indústrias de Calçados - ABICALÇADOS foi a única entidade coletiva no segmento de moda bem-sucedida na escolha da natureza, no depósito do pedido e no seu processamento e, por fim, no registro das suas Marcas Coletivas no INPI. Tal iniciativa garante proteção às empresas calçadistas associadas, tendo em vista que terceiros não autorizados estão impedidos de fazer uso das Marcas Coletivas ou até mesmo de imitá-las.

A Associação Brasileira da Indústria Têxtil e de Confecção - ABIT reconhece a relevância da proteção de ativos de propriedade industrial, todavia não explora o potencial existente na natureza da Marca Coletiva, qual seja, multiplicar o uso do sinal pelos associados. Isso fica claro ao ter escolhido naturezas distintas: Marcas de Produto e Marcas de Serviço. Nessas modalidades, a titularidade e o uso são da própria Associação.

A título de comparação, uma pesquisa feita pela ApexBrasil, em 2007, demonstrou que $87 \%$ dos Projetos Setoriais haviam criado uma logomarca para representar os produtos ou serviços de seus setores. Constatou, ainda, que $84 \%$ dos Projetos consideravam importante mencionar a "origem" brasileira dos produtos, o que normalmente se refletia no desenho do logotipo - pelo uso de cores nacionais ou adaptações da bandeira ${ }^{36}$ - e no nome da marca (APEXBRASIL, 2009).

\footnotetext{
${ }^{36}$ Nesse ponto, convém destacar que o inciso I do art. 124 da LPI impede que se registre como marca: brasão, armas, medalha, bandeira, emblema, distintivo e monumento oficiais, públicos, nacionais, estrangeiros ou internacionais, bem como a respectiva designação, figura ou imitação (grifo nosso). Adaptações tais como estilizações, criações que remetem ao original, dando estilo ou forma própria à figura, tornando-a distintiva, são passíveis de se registrar como marca. Por isso, deve-se ter cuidado no momento de criação da pretensa marca para que ela possa ser efetivamente protegida.
} 


\section{OS PAÍSES ESTRANGEIROS ESTUDADOS E A BUSCA PELA PROTEÇÃO COMO MARCA NO INPI BRASILEIRO}

Conforme discorrido anteriormente, existem três formas de um país ter a imagem associada a uma marca: uso de marcas individuais para diferentes produtos, sem menção explícita do país de origem; uso de marcas e submarcas, com a combinação do nome da marca com o país de origem; e, ainda, o uso conjunto da marca com o local de origem.

Um levantamento dos requerentes individuais - italianos e norte-americanos na indústria da moda - foi realizado na Base de Dados de Marcas do INPI brasileiro. Constatou-se que desde o início da década de 1990 até hoje os Estados Unidos têm uma política externa de proteção individual de marcas na indústria da moda quatro vezes superior que a da Itália (5.958 marcas norte-americanas de produto $\times 1.379$ marcas italianas de produto $\left.{ }^{37}\right)$. Cada um desses países possui somente uma Marca Coletiva registrada no segmento estudado, conforme se depreende no Quadro 3 abaixo:

Quadro 3 - A intenção de entidades coletivas estrangeiras pelo registro de Marcas Coletivas no Brasil

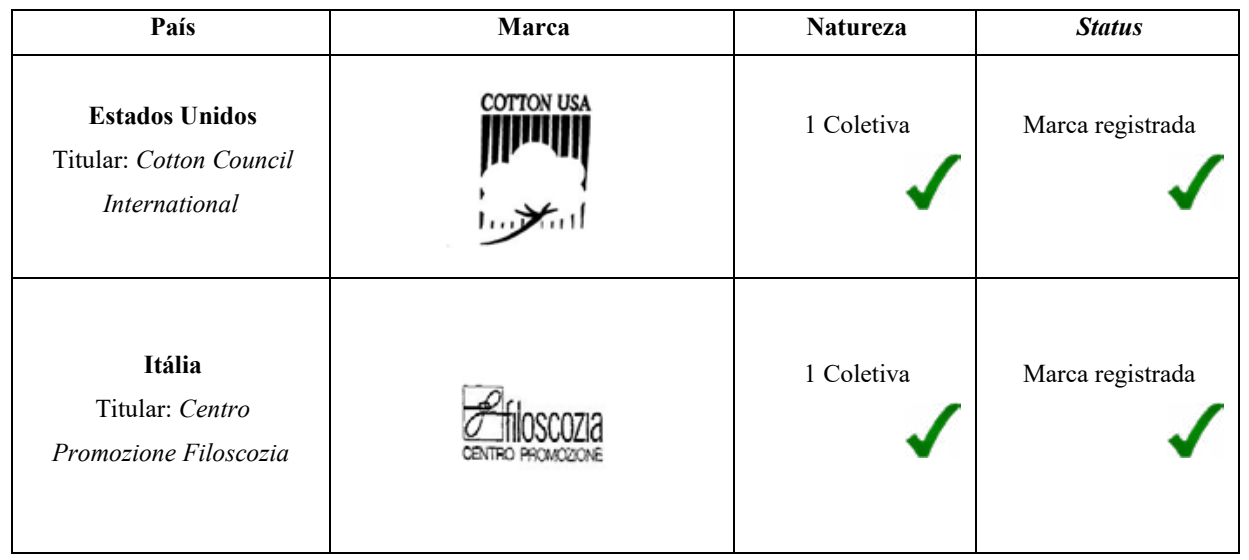

Fonte: Base de Dados de Marcas. INPI (s.d.).

\footnotetext{
${ }^{37}$ Cumpre ressaltar que as marcas são registradas para segmentos mercadológicos divididos de acordo com a Classificação Internacional (NICE) de Produtos e Serviços para o Registro de Marcas (NCL). As classes que protegem os produtos aqui estudados são as 18,23 e 25 , as quais foram as classes-base do estudo.
} 
Assim, pode-se inferir que a macrotendência vem sendo no sentido de empresários norte-americanos e italianos da indústria da moda entrarem cada um por si no mercado brasileiro. Aparentemente, essa postura não vem sendo seguida à risca por empresários do Brasil em busca de novos mercados no exterior. $\mathrm{O}$ apoio da ApexBrasil a Projetos e Subprojetos Setoriais e o registro de suas marcas no INPI demonstram que existem esforços governamentais para alavancar as vendas do setor para além das fronteiras brasileiras. Os autores consideram, ainda, que se a natureza da marca for coletiva em termos das vantagens competitivas antes evidenciadas, certamente a união dos empresários da moda made in Brazil fará a força.

\section{CONSIDERAÇÕES FINAIS}

Incrementar a participação brasileira no posicionamento global é sempre um desafio. As características de cada economia-alvo devem ser levadas em consideração quando do estabelecimento de estratégias adequadas. O Brasil vem buscando apoiar projetos específicos que talvez não gerem um volume elevado de exportações em termos relativos ao que é produzido globalmente.

Mas, talvez, o mais adequado seja focar em mercados específicos que tenham um poder de aquisição voltado para produtos diferenciados que valorizem mais a marca e a qualidade do que o simples atributo de baixo custo financeiro. Nesse sentido, as marcas, que trazem a reboque justamente essa capacidade de diferenciação, podem ser ferramentas fundamentais para que os empresários consigam superar a concorrência de países como a China.

O estudo iniciou com o objetivo de efetuar uma comparação em campos econômicos específicos - artefatos de couro, calçados e acessórios, têxteis e confecções - e mostrar o desenvolvimento de políticas de promoção à exportação para os bens ali elencados. Para tanto, além do Brasil, os países eleitos foram Estados Unidos e Itália.

A primeira inferência extraída desse exercício é a distinta abordagem adotada pelo Governo Brasileiro, por intermédio da ApexBrasil, em relação às entidades congêneres dos outros países apontados, ambos membros do grupo de países desenvolvidos. No Brasil, há uma lógica indutora do desenvolvimento por parte do Governo, que tem sua atuação mais forte nos grupos econômicos 
representados por associações de classe nos chamados Projetos e Subprojetos Setoriais.

Em contraposição, nos Estados Unidos e na Itália, a diretriz de atuação possui um caráter passivo, isto é, são apresentadas pelos governos ferramentas de apoio a todos os setores industriais. Aqueles, suficientemente organizados, poderão tomar a iniciativa de utilizá-las ou não.

No caso norte-americano, segue-se a cultura do empreendedorismo - do it by yourself - e do Estado mínimo, atuando como apoiador da iniciativa privada, enquanto que no caso italiano a relevância dos setores apontados pode variar. No entanto, o fato é que os atores desse país europeu já possuem grande experiência no segmento em questão, ou seja, o mundo da moda, o que poderia tornar desnecessária uma inserção mais ativa do Estado na condução dos negócios.

Cada um por si ou todos por um, o importante é que a política econômica de inserção em mercados externos mostre-se eficaz. No Brasil, o desenvolvimento dos Projetos e Subprojetos Setoriais pode servir, realmente, como facilitador para a inserção das marcas brasileiras no mercado internacional, pelo menos nos setores analisados. A conjunção de esforços, tendo como norte uma marca que agregue a imagem de todo um grupo setorial, em especial vinculando-o a uma determinada origem, tende a fortalecer e a facilitar a identificação de oportunidades comerciais para seus participantes.

A Marca Coletiva se encaixa bem nessa visão, surgindo como uma estratégia de proteção e agregação de valor aos produtos da indústria da moda. Ficou demonstrado que todos os países estudados têm ao menos uma iniciativa nesse sentido, o que ainda se revela muito pouco diante da quantidade superior de marcas individuais. A pergunta que fica é se tal volume, por si só, garante o desenvolvimento do setor ou se corre o risco de ficar "fragmentado", sem políticas que o norteiem, principalmente quando o foco é a busca por mercado externo.

A opção por uma marca de uso coletivo pode ser o caso no qual o todo é maior que o somatório das partes. Há que se atentar que as externalidades podem influenciar o resultado alcançado, seja positivo ou negativo. Isso porque, mesmo havendo esforço coletivo e o devido planejamento, pode haver uma pedra ou outra no caminho que dificulte a trajetória de sucesso.

É importante, certamente, buscar a proteção da marca. Isso representa um dos primeiros passos para quem pretende se diferenciar de seus 
concorrentes, já que se trata de um bem intangível que distingue produtos e serviços de outros idênticos, semelhantes ou afins.

Por sua vez, uma Marca Coletiva significa que os produtos ou serviços provêm de uma entidade e das pessoas ou empresas que a compõem. Pode ser uma estratégia valiosa, especialmente para os late comers, que devem buscar sua inserção em mercados com concorrentes que, muitas vezes, já possuem sua posição consolidada. Nesse contexto, reduzem-se os custos em ações de marketing, essenciais para atrair os consumidores. Desfrutando de esforço coletivo, são grandes as chances de superar os desafios, que não são poucos quando o assunto é lançar moda mundo afora.

\section{REFERÊNCIAS BIBLIOGRÁFICAS}

AGÊNCIA BRASILEIRA DE PROMOÇÃO DE EXPORTAÇÕES E INVESTIMENTOS APEXBRASIL. Termo de Referência para Desenvolvimento da Gestão de Marcas Setoriais: Branding. Brasília, DF: ApexBrasil, 2009. Disponível em: <http://wiki. apexbrasil.com.br/@api/deki/files/714/=Final_BRANDING_Termo_de_Referencia.pdf>. Acesso em: 25 ago. 2016.

AGÊNCIA BRASILEIRA DE PROMOÇÃO DE EXPORTAÇÕES E INVESTIMENTOS APEXBRASIL. Demonstrativo Financeiro de 31 de março de 2016. Disponível em: <http://www.apexbrasil.com.br/uploads/marc\%CC\%A7o-2016.pdf>. Acesso em: 12 ago. 2016.

AGÊNCIA PARA A INTERNACIONALIZAÇÃO DAS EMPRESAS ITALIANAS - ICE. Sem data de publicação. Disponível em: <http://www.italtrade.com/countries/links/ industries.htm>. Acesso em: 22 set. 2016.

ASSOCIAÇÃO BRASILEIRA DA INDÚSTRIA TÊXTIL E DE CONFECÇÃO - ABIT. Perfil do Setor. Sem data de publicação. Disponível em: <http://www.abit.org.br/ cont/perfil-do-setor>. Acesso em: 5 jul. 2016.

BARBOSA, P. M. S.; REGALADO, P. F. Determinação de origem, empoderamento dos produtores, redução de custos, riscos e desenvolvimento local: os múltiplos usos da marca coletiva nos mercado de café. In: SIMPÓSIO DE PESQUISA DOS CAFÉS DO BRASIL, 8., 2013, Salvador. Anais... Salvador: SBICafé, 2013. 5 p. Disponível em: <http://www.sapc.embrapa.br/arquivos/consorcio/spcb_ anais/283.pdf>. Acesso em: 25 ago. 2016. 
BRASIL. Controladoria Geral da União. Secretaria Federal de Controle Interno. Relatório de Auditoria Anual de Contas - Apex-Brasil 2012. Relatório $\mathrm{n}^{\circ}$ 201308611. Brasília, DF, 26 de fevereiro de 2013. Disponível em: <http://www. cgu.gov.br/relatorios-antigos/RA201308611>. Acesso em: 12 ago. 2016.

BRASIL. Instrução Normativa INPI/PR n 19 , de 18 de março de 2013. Dispõe sobre a apresentação e o exame do regulamento de utilização referente à marca coletiva. Brasília, DF, 18 de março de 2013. Disponível em: <http://www.inpi. gov.br/legislacao-1/instrucao_normativa_19-2013_-_regulamento_de_utilizacao.pdf>. Acesso em: 26 ago. 2016.

BRASIL. Lei n 9.279 , de 14 de maio de 1996. Regula direitos e obrigações relativos à propriedade industrial. Diário Oficial [da] República Federativa do Brasil. Brasília, DF, 15 de maio de 1996. Disponível em: <http://www.planalto.gov.br/ ccivil_03/leis/19279.htm>. Acesso em: 26 ago. 2016.

BRASIL. Portal Brasil. Brasil promove produtos de moda e design no mercado norte-americano. Publicado em: 17 de abril de 2012. Disponível em: <http:// www.brasil.gov.br/governo/2012/04/brasil-promove-produtos-de-moda-e-design-no-mercado-norte-americano>. Acesso em: 22 set. 2016.

BRASIL BY BAGS. Comitê Gestor do Bags by Brasil apresenta resultados do trimestre. Publicado em 20 de abril de 2016. Disponível em: <http://www.bagsbybrasil.com/noticia/comite-gestor-do-bags-by-brasil-apresenta-resultados-do-trimestre>. Acesso em: 24 jun. 2016.

BRAZILIAN FOOTWEAR. Sem data. Disponível em: <http://www.brazilianfootwear.com>. Acesso em: 24 jun. 2016.

CAPELLARO, A. F. O desenvolvimento de marcas setoriais no Brasil: uma análise comparativa. 2013. 110 f. Dissertação (Mestrado em Administração de Organizações) - Universidade de São Paulo, Ribeirão Preto, 2013.

CASTELLS, M. A Sociedade em Rede. Vol. 1. Tradução de Roneide Venancio Majer, com a colaboração de Klauss Brandini Gerhardt. 8. ed. São Paulo: Paz e Terra, 2005.

CHESNAIS, F. A globalização e o curso do capitalismo de fim-de-século. Tradução de Catherine Marie Mathieu. Economia e Sociedade, Campinas, n. 5, p. 1-30, dez. 1995.

COUROMODA. Projeto Brazilian Footwear 2015/16: setor está preparado para quebrar paradigmas. Publicado em 13 de janeiro de 2015. Disponível em:<http:// 
www.couromoda.com/noticias/ler/projeto-brazilian-footwear-2015-16-setor-esta-preparado-para-quebrar-paradigmas>. Acesso em: 24 jun. 2016.

EXPORT.GOV. Textiles, Apparels and Sporting Goods. Sem data de publicação. Disponível em: <http://www.export.gov>. Acesso em: 27 jun. 2016.

G1. Saiba o que é comércio exterior. Publicado em 01 de junho de 2010. Disponível em: <http://g1.globo.com/economia-e-negocios/noticia/2010/06/saiba-o-que-e-comercio-exterior.html>. Acesso em: 5 jul. 2016.

INFOMERCATIESTERI. Highlights. Sem data de publicação. Disponível em: $<$ http://www.infomercatiesteri.it/shighlights.php?id_settori=16>. Acesso em: 28 jun. 2016.

INSTITUTO NACIONAL DA PROPRIEDADE INDUSTRIAL - INPI. Marcas. Sem data de publicação. Disponível em: <http://www.inpi.gov.br/menu-servicos/marcas>. Acesso em: 22 set. 2016.

INSTITUTO NACIONAL DA PROPRIEDADE INDUSTRIAL - INPI. Sem data de publicação. Disponível em: <http://www.inpi.gov.br>. Acesso em: 8 set. 2016.

INTERNATIONAL TRADE ADMINISTRATION. About the International Trade Administration. Overview. Sem data de publicação. Disponível em: <http://trade.gov/ about.asp>. Acesso em: 27 jun. 2016.

ITALIAN MODA. Sem data de publicação. Disponível em: <http://www.italianmoda.it/>. Acesso em: 28 jun. 2016.

ITALIAN TRADE AGENCY - ITALTRADE. The Made in Italy Official Portal. Sem data. Disponível em: <http://www.italtrade.com>. Acesso em: 28 jun. 2016.

IVERSEN, N.; HEM, L. E. Provenance association as core values of place umbrella brands: A framework of characteristics. European Journal of Marketing, v. 42, n. 5/6, p. 603-626, 2008.

LOURENÇÃO, M. T. A.; GIRALDI, J. M. E. Processo de Desenvolvimento e Gestão de Marcas Setoriais: Uma Análise da Marca Brazil Gems and Jewelry. Revista de administração da UNIMEP, v. 13, p. 125-153, 2015. Disponível em: <http://www. regen.com.br/ojs/index.php/regen/article/view/945>. Acesso em: 28 jun. 2016. LUPATINI, M. P. As Transformações Produtivas na Indústria Têxtil-Vestuário e seus Impactos sobre a Distribuição Territorial da Produção e a Divisão do Trabalho Industrial. 2004. 152 f. Dissertação (Mestrado em Política Científica e Tecnológica) - Universidade Estadual de Campinas, Campinas, 2004. Disponível 
em: <http://repositorio.unicamp.br/jspui/bitstream/REPOSIP/286805/1/Lupatini_MarcioPaschoino_M.pdf>. Acesso em: 28 jun. 2016.

MADE-IN-ITALY.COM. The Excellence of Italian Products. Sem data de publicação. Disponível em: <http://www.made-in-italy.com/>. Acesso em: 28 jun. 2016.

PORTAL ICE. Disponível em: <http://www.italtrade.com/countries/links/industries.htm>. Acesso em: 22 set. 2016.

REGALADO, P. F. et al. Uma inovadora interação entre INPI, ApexBrasil e o mercado: As Marcas Coletivas Setoriais In: ENCONTRO ACADÊMICO DE PROPRIEDADE INTELECTUAL, INOVAÇÃO E DESENVOLVIMENTO, 8., 2015, Rio de Janeiro. Anais... Rio de Janeiro: INPI, 2015.

SINDIVESTUÁRIO. China ultrapassa Estados Unidos como maior mercado de vestuário e calçados. Publicado em 2014. Disponível em: <http://sindivestuario.org.br/2014/06/china-ultrapassa-estados-unidos-como-maior-mercado-de-vestuario-e-calcados/>. Acesso em: 12 ago. 2016.

TEXBRASIL. Programa de Internacionalização da Indústria da Moda Brasileira. ApexBrasil e ABIT assinam novo convênio para o Texbrasil. Publicado em 11 de julho de 2013. Disponível em: <http://texbrasil.com.br/pt/apex-brasil-e-abit-assinam-novo-convenio-para-o-texbrasil-2/>. Acesso em: 24 jun. 2016. 